\title{
The Degradation of the Reasons and Countermeasures of Coastal Wetlands Ecosystem in Beibu Gulf*
}

\author{
Wei Huang \\ Guangxi Key Laboratory of Beibu Gulf Marine Biodiversity \\ Conservation \\ Guangxi colleges and universities Key Laboratory of \\ Exploitation and Protection of Beibu Gulf Marine \\ Biological Resources \\ Qinzhou University \\ Qinzhou, China \\ E-mail: hww908i@foxmail.com
}

\author{
Zhilian Fan \\ College of agriculture \\ Guangxi University \\ Nanning, China \\ E-mail: 464259744@qq.com
}

\author{
Daobo Wang \\ Guangxi Key Laboratory of Beibu Gulf Marine Biodiversity \\ Conservation \\ Guangxi colleges and universities Key Laboratory of \\ Exploitation and Protection of Beibu Gulf Marine \\ Biological Resources \\ Qinzhou University \\ Qinzhou, China \\ E-mail: d.b.wang@foxmail.com
}

\author{
Liangyu Mo \\ College of agriculture \\ Guangxi University \\ Nanning, China \\ E-mail: 1377683209@qq.com
}

\begin{abstract}
From human activities such as aquaculture, industry and tourism perspective, the status of development and utilization of the coastal wetland in Beibu gulf were discussed. Then, the degradation of the coastal wetland ecosystem in Beibu gulf were analysis: unreasonable reclamation such as the coastal wetlands coastal breeding failure, unreasonable grazing and poultry, port development and construction; offshore pollution aggravation; excessive use of biological resources such as excessive digging edible invertebrates and excessive collection bait factors. At last, the countermeasures and the recovery of Beibu gulf coastal wetland protection were put forward, namely: improving and implementing the protection of the ecological environment of coastal wetland system of laws and regulations; to further strengthen the construction of coastal wetland protection area; restoration and protection of coordinated economic development and coastal wetland; strengthening basic research in coastal wetland ecosystem restoration technology.
\end{abstract}

Keywords-coastal wetlands; Mangrove; Beibu gulf; protection countermeasures

\section{INTRODUCTION}

The Beibu gulf coastal wetland mainly includes Qinzhou, Beihai and Fangchenggang bay coastal zones, rivers, estuaries and winding harbour, intertidal beach, mudflats, mud and sand. There are many small mouths and a lot of small offshore islands. The Beibu gulf coastal wetland types, mangrove wetland has been listed in the list of important wetland in

Fund Project: Guangxi Key Laboratory of Beibu Gulf Marine Biodiversity Conservation Foundation/ Guangxi colleges and universities Key Laboratory of Exploitation and Protection of Beibu Gulf Marine Biological Resources Foundation (2015ZB09, 2015KA02)

Communication author: Wang Daobo, Fan Zhilian
China, have Shankou mangrove national nature reserve, Shatian dugongs national nature reserve, Beilunhekou mangrove national nature reserve, Maoweihai mangrove national nature reserve. According to the survey of the mangrove resources in 2001,Guangxi Beibu gulf existing contiguous distribution area of more than $0.1 \mathrm{hm}^{2}$ mangrove patches 863 , with a total area of $8374.9 \mathrm{hm}^{2[1]}$, main distribution in the Maoweihai, Tieshan port, Dafengjiang, Fangchenggang East Bay and Dandouhai. Bay natural species variety, a total of 8 families and 11 kinds of true mangrove,

half mangrove 6 families, 8 species, accompanying plants have 12 families and 14 species $^{[2]}$, the macrozoobenthos species are mollusks, crustaceans, arthropods, fish, polychaetes, gastropods, etc., also have a variety of algae and zooplankton. The unique geographical conditions and rich natural resources of mangrove wetlands in the Beibu gulf, the animals that were attracted by deep water area to the mangrove areas in the feeding habitat and breeding, and have a wealth of bird food resources, is migratory birds wintering grounds and migration of the station, but also various seabirds breeding, growth and habitats.

\section{CURRENT Situation of DEVElopment AND Utilization of COASTAL WeTLANDS IN BEIBU GULF}

\section{A. Aquaculture industry situation of coastal wetlands}

1) Mangrove mariculture, reclaiming land from the sea

The coastal wetlands in the Beibu Bay are of various types of mangroves, which belong to the mudflats intertidal zone, 
and the biological species are abundant, and the contents of the basal nutrients are high and there along with the tidal water level changes. Due to its unique ecological environment, the local farmers often scarf forest cultivation, in the region from activities ${ }^{[3]}$, such as oysters row, shrimp and so on.

\section{2) Extract edible invertebrates}

Mangrove wetland has been the traditional Marine growth, the growth of the Beibu gulf coastal wetland mudflats and beach features seafood mainly includes sandworm (Sipunculus nudus), mudskipper (Periophthalmus cantonensis), mantisshrimp (Oratosquilla oratoria), crab (Brachyura), oyster (ostrea gigas thunberg), and a variety of shellfish and so on.These features seafood all have high value goods, many local farmers as the main economic source.

\section{3) Grazing and poultry farming}

The pigs and ducks that growing in the seaside and the ancillary products is one of the specialty of the Beibu gulf coastal areas. Mangrove plants can be used as feed, the three cities of Beihai, Qinzhou, Fangchenggang, a good environment for grazing pigs, cattle, sheep and poultry breeding, near the farmers to reduce the cost of feeding, frequent grazing or culture in the mangrove growing areas.

\section{4) Collect bait}

Tidal mangrove wetlands grow a wide variety of small snails, in recent years, these small snails are a large number of acquisitions, part of the sold in the market, while others are crushed as a supplemental feed shrimp. North Bay area put these small snails crush popular as the delicious ingredient consumption.

\section{B. Current situation of coastal wetlands in Industrial Development}

In recent years, Guangxi implementation of coastal infrastructure General Assembly war, the use of coastal wetlands development industry, mainly the construction of Fangchenggang, Qinzhou port, Tieshan port, Shatian port and so on, which Qinzhou port is a national Bonded Harbor. Qinzhouwith excellent location and has a high quality environment for the rapid development of its industrial port provides many necessary conditions. Qinzhou port economic and technological development zone is located in the south coast, Guangxi Qinzhou jurisdiction area of $152 \mathrm{~km}^{2}$, mainly planning and construction of petrochemical industrial park, comprehensive logistics processing zone, administration in the central business district and port areas, etc. Qinzhou port has been built into China's sixth coastal bonded port area, Qinzhou bonded harbor area, the port is the only one of China's western coastal bonded port area, it was being reclaimed from the sea reached $3 \mathrm{~km}^{2}$.According to the geological investigation circumstances indicate that Qinzhou Port planning shoreline about $60.8 \mathrm{~km}$, have been built a ton waterway, mainly has bonded port, Da wharf, Zhongshan port, the dragon pier, Yulong wharf, etc. Planning 12 operating area, 1-30 ton deepwater berths can be built about 200, of which 10-30 tons of large deep-water berths over 30. November 2010, the State Council approved, caused a new round of development boom.

\section{Status quo of tourism}

Beihai is one of the traditional tourist cities, Fangcheng port and Dongxing tourism also performed well, Qinzhou also the tourism industry as the key to grasp. The heat in winter and cool in summer, a pleasant climate, near mountains and sea, is a treasure of the Golden Triangle southern coastal on China. Numerous rivers and lakes in Beibu port, fertile soil, lush plants, abundant natural resources, mountain green water show, in coastal water, mountains and rivers beautiful, charming scenery. Qinzhou tourism, though starting late, here beautiful scenery, numerous historical, splendid cultures, since ancient times has become GuiNa region famous tourist resort. Qinzhou tourist attractions there are more than 30, 4A level scenic spots, which involves the main coastal wetlands are: Sanniangwan tourist area, Malanisland, Longmen islands, Sanhaiyan and so forth. The scenic spots in selling handicrafts, parking charges, operating restaurants, hotels, small supermarkets and so on. The tourism project of the solid waste produced in, accommodation and catering sewage and cruise ship oil pollution, overfishing on natural resources and use, to the coastal wetland environment and damage to natural resources.

\section{The Reason of the Beibu Gulf CoAstal WetLand ECOSYSTEM DEGRADATION}

The degradation of the coastal wetland ecosystem in Qinzhou is due to the reclamation and improvement of the coastal wetlands, the increasing pollution of the coastal waters, and the excessive use of biological resources.

\section{A. Unreasonable reclamation and reconstruction of coastal wetland}

Beibu gulf Coast is in the economic activity area, facing the industry, real estate, aquaculture and tourism development of the strong pressure, blind, excessive reclamation and transform the phenomenon more serious. Some coastal engineering construction in irrational and destructive behavior, to some extent increase or change the tide and wave activity mode, lead to increasing the erosion of the range, the damage to the coastal wetland ecosystems.

\section{1) Offshore aquaculture damage}

Deforestation is the development of mariculture is currently the main mode of the Beibu gulf destructive use of coastal wetlands, in recent years, the breeding pond are very popular disastrous damage to the mangrove wetland resources ${ }^{[4]}$. For example Qinzhou as famous oyster place, using offshore by oyster breeding, damage to the coastal wetland ecological environment and affected the waterways; Beihai as a traditional prawn breeding base, clearing of mangroves farmed shrimp is very common, even the Shankou town Hepu country borders on Guangdong, many mangroves have been developed by Cantonese. At the same time, large tidal flats is used for pond farming sandworms, crabs and other seafood, vegetation restoration and protection of the mangrove wetland is very $\operatorname{adverse}^{[5-6]}$.

\section{2) Unreasonable grazing and poultry farming}

Beibu gulf mangrove wetland is mainly composed of Aegiceras (Aegiceras corniculatum (L) Blanco.), Avicennia manna (Aviccenia marina (Forsk) Vierh.), Kandelia (Kandelia 
candel (Linn.) Druce.), Bruguiera (Bruguiera gymnorrhiza (L.) Poir.), Rhizophora stylosa (Rhizophora stylosa), Excoecaria agallocha (Excoecaria agallocha Linn.) and so on.Wherein A.marina, K.candel be local villagers as cattle, sheep, pigs, ducks and other supplemental feed. Today, the sea has become a large-scale breeding duck, its eggs has also become one of the specialty of the Beibu gulf, at the same time, Beihai Silver Beach Eastern mangrove excessive aquaculture sea ducks, resulting in the death of large tracts of mangrove forests, the problem caused widespread concern. Although poultry restocking in the mangrove areas will not cause significant direct impact on the coastal wetland plants, but the mangrove wetland ecosystem biodiversity conservation is very unfavorable. In addition, the pork is a dish of the Beibu gulf $^{[7]}$. Due to the pigs, cattle, sheep, and other livestock trampling, many places, artificial afforestation complete failure of cattle and sheep eating also make the trend of mangrove wetlands dwarf and sparse, community to natural regeneration.

\section{3) The port development and construction}

Port construction waste generated by the construction of a substantial increase, with the augment of ship, the resulting flow of oil pollution, waste water, sewage, garbage, etc make the Qinzhou port environment by a certain degree of pollution. In recent years, the Beibu gulf economic development and construction in full swing, port development, urban construction and industrial construction activities cause serious damage to the coastal tidal flats. 2014, high-strength typhoon, making Beihai, Qinzhou, Fangchenggang coastal wetlands suffer great damage, seawall also dangerous situation, heightening and strengthening dikes and repair the seawall requires large amounts of earth and rock, need a lot of engineering are formed mainly of mangrove tidal flat soil in front of dike, indirect destroyed the coastal wetland before the dam, caused the mudflat elevation is descended by $15-30 \mathrm{~cm}$. Engineering stone is mostly transported by maritime transport, shipped from a distance, in order to the ships of the stone can close to the seawall when high tide level, cut down a bank before 5-30 $\mathrm{m}$ within the scope of the mangrove forest in late succession. Periodic anthropogenic interference caused the mangrove hard to recover from the natural succession, degeneration of coastal wetland ecosystem.

\section{B. Offshore pollution aggravate}

Coastal wetlands as a bearing area of land-based pollutants bear the city to the discharge of pollutants, including the urban sewage, agricultural fertilizers and pesticides, industrialization and urbanization in the unreasonable processing waste, and produce all kinds of garbage in the tourism industry, etc $^{[8]}$. These man-made pollution has seriously affected the material circulation of the coastal wetland ecosystem in the Beibu gulf, and through the food chain affect the enrichment of coastal wetland biological resources.

Beibu gulf emissions continue to increase, but the people of the coastal wetland protection consciousness doesn't improve, the pollution control facilities construction and the measures to keep up with, which leads to pollution directly affect coastal wetland ecosystem. Such as, several ports are present sewage problem, and because of backward farming techniques (Farmers generally used diesel engine as the powerfor oxygen to aquaculture ponds and water and drain system, and drip diesel engine is more serious),cause culture zones of petroleum pollution in seawater. Coastal tourism produce huge amounts of waste discharge directly, and some whelks farmers abuse of highly toxic drugs, to aquaculture sea area and adjacent sea area has brought serious consequences, cause part of ecological area is in failing health, pose a threat to mangrove ecosystem, seaweed bed and so on. The contents of inorganic nitrogen and inorganic phosphorus increased in the Beibu Gulf. These all can change the original ecological environment, change the chemical properties of the water, reduce the dissolved oxygen, polluted water, led to the deaths of endemic species, and even extinction ${ }^{[9]}$, thus triggering a series of environmental problems and ecological deterioration.

\section{Excessive use of biological resources}

\section{1) Excessive poaching edible invertebrates}

The mangrove wetland in mining economy seafood, especially the sandworms, is a major way of making money by residents. Mangrove wetlands have $30 \%$ of the area was continuing excavation, the annual number of mining the higher reaches dozens of times. Mining activities periodically destroyed the mangrove plant root system, the lack of forest nutrient supply, growth has stagnated, gradually dwarf and sparse, and some even into death. Mining and stampede also greatly endanger forest seedlings and saplings, making it difficult natural regeneration growth. In addition, the mining activities also undermines the habitat of Marine benthic animal life ${ }^{[10]}$, the economy declines animals.

\section{2) Excessive collection bait}

The small snail growth in the Beibu Gulf coast wetland is the main food of the offshore predators, reduction in the number of its will reduce the output of the economic value of higher predators. Excessive collection of bait, not only the direct destruction of wetlands, especially the mangrove ecosystem, but also reduces the productivity of mangrove wetland ecosystem. Along with the reduction of the area of the coastal mangrove wetland and the destruction of the ecological environment, the natural production of the economic animal in the coastal area of Guangxi has dropped by $60 \%-90 \%$.

\section{The Beibu Gulf Coastal WetLand Protection AND RECOVERY MEASURES}

\section{A. Perfect and earnestly implement the laws and regulations system of coastal wetland ecological environment protection}

Learn from the experience of other provinces, to avoid unnecessary detours, as soon as possible to carry out comprehensive survey of near shore natural resources and environment. On this basis, strictly carrying out the "Marine environmental protection law", "maritime space use administration law" and the "China ocean agenda in the $21 \mathrm{st}$ century", and other national laws or regulations, to develop "Beibu gulf operation management measures", "Guangxi aquatic wildlife protection regulations" and other related local regulations and regulations. Beibu gulf cities can also be combined with its own specific conditions, form a complete set for the corresponding laws and regulations, make the Beibu 
gulf coastal wetlands must be regulated. Related departments should establish and improve the wetland strictly in accordance with these laws and regulations enforcement system, in accordance with one hand grasping construction, with anther hand grasping protection, strengthening the management of coastal Marine environmental law enforcement and supervision agencies, to reverse the Beibu gulf Coast wetlands continue to be destroyed and increasingly reduced situation.

\section{B. To further strengthen the construction of coastal wetland reserve}

To is severely threatened or damage, but it has not been attention and protection of coastal wetlands, the Beibu gulf each related government and relevant departments should speed up the planning and the establishment of coastal wetland nature reserve. In accordance with the nature reserve management regulations of the national or provincial, based on the experience of the nature reserves have been built, detailed regulations for protection and control pollution and reduce the damage, protect and restore the region of coastal wetland ecosystem and species diversity.

To have been built several national coastal wetland nature reserve and national forest park, should be improve the management mechanism, in strict accordance with the regulations, carry out investigation, monitoring, to carry out the relevant scientific research, formulate protection measures, such as increasing the investment of funds and management, make reserve get real recovery and protection. The number and size of the existing reserve is relatively more, but can not only satisfy the status quo, as compared with the entire northern Gulf coast zone, far from enough, it is necessary to intensify the building of reserves and the radiative zone.

\section{Coordinate economic development and coastal wetland with the relationship between the restoration and protection.}

The unreasonable utilization of coastal wetland is one of the main human factors in the degradation of coastal wetland ecosystem, the sustainable development of coastal wetland must correctly handle the development and utilization and the relationship between coastal wetland ecosystem conservation and restoration. Therefore, it must be scrupulous implementation of relevant laws and regulations of the country and the region, research capacity of the various marine environments, strict formulate and seriously implement quota of total control, control of urban life waste, industrial pollutants, tourism waste emissions, control the scale of farming and especially emissions. Relevant departments should adhere to the principle of "protection first, ecological friendly, rational development, sustainable use" approach, scientific establishment of Beibu gulf coastal wetland utilization and protection planning. Make full use of the new method of spatial information science and technology, strengthen the monitoring of coastal wetlands in the Beibu gulf of pollutants, and further study of pollution migration mechanism, explore ways, through the model simulation analysis, establishing reasonable control measures, and carry on the dynamic monitoring of pollutants.
The core area of nature reserves to examine all development activities, the development of other coastal wetland, so as not to damage and do not pollute of the ecological environment, to ensure sustainable utilization of resources as the basic principle, must carry out environmental impact assessment, reasonable use direction of the coastal wetland, achieve the combination of protection and utilization, combining resources exploitation and ecological restoration.

In addition, restoration and protection of the ecological environment of the Beibu gulf not only involved its own development, but also to surrounding areas. North Bay east coast of Guangdong, south across the river in Vietnam, the north against Guangxi basin, through regional cooperation, with the aid of the developed areas of the economy and talent advantages, absorb the successful experience of the ecological construction, united international force, improve the level of ecological protection and management.

\section{To strengthen the basis of the coastal wetland ecosystem restoration technology research}

Each piece of coastal wetland has its unique dominant function, which integrated its geographical conditions, and conditions of genesis, evolution, biological diversity and food webs, natural resources and reserves and other types of decisions. Different damage to coastal wetland ecosystem for different reasons, the extent of damage also is different, the repair should adjust measures to local conditions, targeted, on the basis of detailed investigation in combination with scientific knowledge, with reference to the experience of other regions, a reasonable set of coastal wetland ecosystem restoration strategy, achieves the twice the result with half the effort. Focus on the following two aspects:

1) How to protect the Beibu gulf coastal wetlands and recovery, pay attention to the following contents:

The study of the Beibu gulf coastal wetland biodiversity and its habitat; Studies on the selection, cultivation and afforestation techniques of mangrove species; Study on coastal wetland environmental carrying capacity and self purification capacity of the Beibu gulf; The study of waste ponds, unreasonable enclosureecological restoration; Improve and enhance the seagrass bed of habitat and the recovery of damaged parts.

2) To solve the problem of coastal pollution, pay attention to the following contents:

The characteristics of the ecological system in the Beibu Gulf, the requirements of the breeding object, the influence of the culture on the environment, and the estimation of the culture capacity; Set standard of offshore aquaculture wastewater discharge; Study on biological degradation of organic pollutants in aquaculture ponds; Clean breeding technology research and so on.Units

\section{REFERENCES}

[1] C.G. Li. The distribution of number of mangrove forests in Guangxi Province. Journal of Beijing Forestry University, vol. 26, pp. 47-52, January 2004. 
[2] S.Q. Xu, J.M. Li, S.B. Lu, et al. Status and sustainable development strategy of Mangrove Resources in the Beibu Gulf of Guangxi Province. Biological bulletin, pp. 11-14, May 2010.

[3] H. Lin. Research of Beibu Bay aquaculture industry sustainable development strategy in Guangxi Province. Guangxi Normal University, 2013.

[4] J. Lv. The effect of pond culture on mangrove ecosystem in China. Environmental Science Society of China. pp. 63-64, May 2013.

[5] H.F. Ma and Y.J. Zhang. Research on the impact of aquaculture on water environment. Chinese fish society, China Water Conservancy Technology Information Center, national Freshwater Fisheries Research Center (Wuhan), Chinese Academy of Fishery Sciences, second, China. pp. 4-10, July 2010.

[6] J.L. Li, G.Y. Wang and S. Qin. The effect of offshore aquaculture on microbial community diversity in the intertidal zone of Qinhuangdao. Journal of ecological environment. vol. 20, pp. 920-926, May 2011.

[7] D.B. Wang and X.G. Zhou. The current situation and suggestion of the development of the villagers' participation in the development of mangrove ecological tourism in eastern Silver Beach. Anhui Agricultural Sciences, vol. 39 pp. 3454-3455, 3457, June 2011.

[8] L. Zhang. On the China offshore pollution problem. Journal of Jiangsu Institute of Education (Natural Science Edition), pp. 27-29. April 2009.

[9] C.G. Ma, L.L. Xu, W. Tian, et al. Impact of reclamation of the east beach wetland benthic animal in Nanhui. Acta ecologica Sinica, vol. 31, pp. 3-11, April 2012.

[10] Y. Zhang, Z.B. Lv, Z.F. Xu, et al. Effects of environmental pollution on the diversity of the benthic fauna in the Xiaoqing River estuary. Journal of ecology, vol. 31, pp.381-387, Feb 2012. 